\title{
Letter to the Editor: Absorption of Iron Calculated from Estimated Changes in Total Body Iron
}

\author{
SAMUEL J. FOMON \\ Department of Pediatrics, College of Medicine, University of Iowa Hospitals, Iowa City, Iowa, USA
}

\begin{abstract}
Garry et al. (1) have used the approach of Saarinen and Siimes (4) to estimate iron absorption from human milk. The approach is based on the assumption that plasma concentration of ferritin bears the same relation to nonhemoglobin body iron stores in the infant as in the adult. This assumption, combined with other assumptions and calculations, led Garry et al. (1) to conclude that during the first 3 months of life breast-fed infants absorbed $81 \%$ of iron from human milk.

Both groups of investigators $(1,4)$ have used a mean concentration of $1 \mathrm{mg}$ of iron per liter of human milk in their calculations. If one utilizes a value of $0.4 \mathrm{mg}$ of iron per liter, which more closely reflects results of studies reported since $1976(2,3,5)$, the calculations lead to the conclusion that well over $100 \%$ of the iron in human milk was absorbed. It therefore seems evident that the approach of Saarinen and Siimes (4) and Garry et al. (1) does not permit valid predictions of iron absorption.

Perhaps in the next few years it will be possible to establish for
\end{abstract}

infants the relation between plasma concentration of ferritin and body iron stores.

\section{REFERENCES AND NOTES}

1. Garry, P. J., Owen, G. M., Hooper, E. M., and Gilbert, B. A.: Iron absorption from human milk and formula with and without iron supplementation. Pediatr. Res., 15: 822 (1981).

2. Franssơn, G.-B., and Lönnerdal, B.: Iron in human milk. J. Pediatr., 96: 380 (1980).

3. Picciano, M. F., and Guthrie, H. A.: Copper, iron, and zinc contents of mature human milk. Am. J. Clin. Nutr., 29: 242 (1976).

4. Saarinen, U. M., and Siimes, M. A.: Iron absorption from breast milk, cow's milk, and iron-supplemented formula: An opportunistic use of changes in total body iron determined by hemoglobin, ferritin, and body weight in 132 infants. Pediatr. Res., 13: 143 (1979).

5. Siimes, M. A., Vuori, E., and Kuitunen, P.: Breast milk iron-a declining concentration during the course of lactation. Acta Paediatr. Scand., 68: 29 (1979).

\section{Letter to the Editor: Response to Dr. Fomon's Letter to the Editor: Absorption of Iron Using a Nonisotopic Method to Estimate Body Storage Iron}

\author{
PHILIP J. GARRY \\ Clinical Nutrition Laboratory, University of New Mexico, School of Medicine, Albuquerque, New Mexico, USA
}

\begin{abstract}
I appreciate Dr. Fomon's comments and concerns about the interpretation presented in our paper dealing with iron absorption from human milk and formula (3). I reviewed Dr. Fomon's comments with my associates and offer the following reply.

As was pointed out in the article, a number of assumptions had to be made in using this new nonisotopic approach as originally proposed by Saarinen and Siimes (6) to estimate the amount of iron absorbed from human milk. A major assumption was that plasma ferritin levels can be used to estimate nonhemoglobin body storage iron (BSI) in infants. In defense of the equation used to estimate BSI from plasma ferritin values $(y=0.0439 \times+1.345$; where $\mathrm{y}=\log$ ferritin $\mathrm{ng} / \mathrm{ml}, \times=\mathrm{BSI} \mathrm{mg} / \mathrm{kg}$ ), it was determined that the mean BSI for 232 newborn infants was $24.8 \mathrm{mg} / \mathrm{kg}$, a value in close agreement with the commonly reported value of 25 $\mathrm{mg} / \mathrm{kg}$ for storage iron of newborn infants (1). Using this equation to estimate BSI in the calculation to predict mean iron absorption from an iron fortified formula $(\mathrm{F}+)$ between ages 3 and 6 months, a value of $3 \%$ was recorded. Using the exact same iron fortified
\end{abstract}

formula containing extrinsic isotopic iron, Rios et al. (5) demonstrated a mean iron absorption rate of $3.9 \%$ in infants of the same age. The agreement between these two entirely different approaches to obtain iron absorption data during the same age period using identical formulas gives credence to the present equation used to estimate BSI.

The fact that our article estimated that infants receiving human milk during the first 3 months of life absorbed $81 \%$ of available iron does not invalidate this technique even though we used a value of $1.0 \mathrm{mg} /$ liter instead of the $0.4 \mathrm{mg} /$ liter suggested by Fomon as the more reasonable value for the iron concentration in human milk during this period. Dr. Fomon is correct in that using an iron value of $0.4 \mathrm{mg} /$ liter for human milk would result in a mean iron absorption value well over $100 \%$ during the first 3 months of life. However, an iron value for human milk of $0.4 \mathrm{mg} /$ liter may be as suspect as the $1.0 \mathrm{mg} /$ liter used in our calculations. For example, Fransson and Lonnerdal (2) recently demonstrated that the concentration of iron in human milk can increase from 
0.3 to $1.0 \mathrm{mg} / \mathrm{liter}$ during the course of a single nursing. This fact and the finding by Siimes et al. (7) that there is a large variation in the iron content in human milk, especially during the first 3 months of lactation, could lead one to believe that mean concentration of iron during a single nursing might easily be in the range of 0.7 to $0.8 \mathrm{mg} /$ liter.

Using a value of $0.75 \mathrm{mg} /$ liter and an average intake of $850 \mathrm{ml}$ human milk per day, instead of $800 \mathrm{ml}$, the mean absorption rate would be approximately $100 \%$. We believe this to be a reasonable estimation considering the high bioavailability of iron in human milk demonstrated by other investigators and the known fact that iron absorption, expressed as a percent of intake, is inversely related to the amount ingested. Also, Gorten et al. (4) demonstrated clearly that iron absorption increases as a function of weight gain expressed in $\mathrm{g} / \mathrm{kg} /$ day. The low concentration of iron in human milk and the high velocity of growth during this period tend to support the observation that iron absorption during the first 3 months of life could approach $100 \%$.

As this nonisotopic method is used by more investigators to predict iron absorption from estimated BSI values, especially at various stages of growth, it may be necessary to re-evaluate the equations which have been used. For the present, both studies using this technique $(3,6)$ give reasonable values for the types of feedings tested when compared with previus studies using isotopic iron.

\section{REFERENCES AND NOTES}

1. Bothwell, T. H., Charlton, R. W., Cook, J. D., and Finch, C. A.: Iron Metabolism in Man, p. 15 (Blackwell Scientific Publications, Oxford, 1979).

2. Fransson, G. B., and Lonnerdal, B.: Iron in human milk. J. Pediatr. 96: 380 (1980).

3. Garry, P. J., Owen, G. M., Hooper, E. M., and Gilbert, B. A.: Iron absorption from human milk and formula with and without iron supplementation. Pediatr. Res., 15: 822 (1981).

4. Gorten, M. K., Hepner, R., and Workman, J. B.: Iron metabolism in premature infants. I. Absorption and utilization of iron as measured by isotope studies. $J$. Pediatr., 63: 1063 (1963).

5. Rios, E., Hunter, R. E., Cook, J. D., Smith, N. J, and Finch, C. A.: The absorption of iron as supplements in infants cereal and infant formulas. Pediatrics, 55: 686 (1975).

6. Saarinen, U. M., and Siimes, M. A.: Iron absorption from breast milk, cow's milk, and iron-supplemented formula: An opportunistic use of changes in total body iron determined by hemoglobin, ferritin, and body weight in 132 infants. Pediatr. Res., 13: 143 (1979).

7. Siimes, M. A., Vuori, E., and Kuitunen, P.: Breast milk iron: A declining concentration during the course of lactation. Acta Paediatr. Scand., 68: 29 (1979)

\begin{abstract}
ANNOUNCEMENT
The annual meeting of the American Society of Pediatric Nephrology will be held at the Sheraton Washington Hotel in Washington, DC on Thursday evening, May 13, and Friday morning, May 14, 1982. The symposium is entitled, "The Role of the Kidney in Calcium and Phosphate Homeostasis." For further information, please contact Dr. Russell Chesney, Secretary-Treasurer, American Society of Pediatric Nephrology, University of Wisconsin Clinical Sciences Center (H4/452), 600 Highland Avenue, Madison, Wisconsin 53792.
\end{abstract}

